\title{
Caregiver-provider communication after resection of pediatric brain tumors
}

\author{
Alexandra Cutillo, PhD, ${ }^{1}$ Kathrin Zimmerman, BA, ${ }^{2}$ Susan Davies, PhD, ${ }^{3}$ Avi Madan-Swain, $\mathrm{PhD},{ }^{4}$ \\ Wendy Landier, PhD, ${ }^{4}$ Anastasia Arynchyna, MPH, ${ }^{2}$ and Brandon G. Rocque, MD, MS ${ }^{2}$
}

\begin{abstract}
${ }^{1}$ Department of Psychology; ${ }^{2}$ Department of Neurosurgery, Division of Pediatrics; ${ }^{3}$ Department of Health Behavior, School of Public Health; and ${ }^{4}$ Department of Pediatrics, Division of Hematology/Oncology, University of Alabama at Birmingham, Alabama
\end{abstract}

\begin{abstract}
OBJECTIVE Because caregivers are a crucial part of a child's medical care, it is important to understand how to best communicate with them during hospitalization. Qualitative research can elucidate the best strategies for effective parent-provider communication. This study aims to reveal communication styles of neurosurgery team members, and to identify areas for improvement in the future.

METHODS Caregivers of children with a newly diagnosed brain tumor requiring neurosurgery were enrolled during their child's hospitalization. During routine follow-up clinic visits within 3 months after diagnosis and tumor resection, caregivers participated in a semistructured interview, which assessed the quality of communication with the neurosurgery and oncology teams during hospitalization. Interviews were audio-recorded, transcribed, and coded for common themes until thematic saturation was reached.

RESULTS During caregiver interviews ( $N=22)$, several domains were discussed including communicating the diagnosis to the patient and siblings, to the rest of the family/support network, and with the neurosurgery team. Regarding parent-neurosurgeon communication, $82 \%$ of caregivers identified at least one positive aspect and $55 \%$ identified at least one negative aspect of communication. Caregivers who provided positive feedback appreciated that their neurosurgeon was thorough (73\%), direct (27\%), or compassionate (14\%). They also valued when providers would speak "on my level" $(18 \%)$ and would speak directly to the patient (27\%). In terms of negative feedback, caregivers identified miscommunications (32\%), discussing the diagnosis in front of the child before feeling prepared to do so (14\%), and a lack of clarity about expectations, medications, or treatment (32\%).

CONCLUSIONS These data provide specific ways in which neurosurgery providers have communicated effectively with caregivers and identify areas for improvement. Results have been used to develop a navigator-led intervention geared toward improving parent-provider communication during hospitalization for resection of a brain tumor.

https://thejns.org/doi/abs/10.3171/2020.4.PEDS19696
\end{abstract}

KEYWORDS pediatric brain tumor; caregiver; brain tumor treatment; communication; oncology

$\mathrm{T}$ HE initial hospitalization and surgical treatment for a child's brain tumor is associated with a variety of potential stressors for both patients and their families. ${ }^{1-3}$ Surgical treatment, although lifesaving, can result in deficits that can impact a child's ability to perform activities of daily living. Surgical treatment can also impact family dynamics, as parents of a child with cancer must struggle to make treatment decisions for their child during a difficult time. Mothers and fathers of children with cancer report levels of stress that exceed cutoffs for posttraumatic stress symptoms, ${ }^{4}$ and previous studies have suggested that the most stressful aspect of having a child with cancer is related to caregivers' inability to control the experience, especially in regard to their child's pain and survival. ${ }^{5}$

Clear communication between parents and the medical team is an essential part of minimizing stress associated with their child's hospitalization and subsequent treatment for a brain tumor. Previous studies have shown that good communication with the medical team is a predictor of healthcare satisfaction, and that patient satisfaction with healthcare is a predictor of medical treatment adherence. ${ }^{6,7}$ However, many factors, such as time constraints or cultural barriers, impair physicians' ability to address questions 
from parents and caregivers during their child's hospital stay. ${ }^{8}$ At large academic hospitals, communication challenges that caregivers face include inconsistencies in communication related to interactions with multiple members of a large interdisciplinary team, confusing messages with a large interdisciplinary team, and perception of their role on family-centered rounds. ${ }^{9}$

Per our literature review, there are no previous reports of qualitative assessment of caregiver-medical team communication and hospital services offered to caregivers of children with a new diagnosis of a brain tumor (i.e., within 2 months of diagnosis). A qualitative investigation of caregiver-medical team communication has the potential to help providers identify specific barriers to communication as well as to design methods to address these barriers. Addressing communication challenges faced by caregivers of a child diagnosed with a brain tumor can potentially increase the quality of care these patients receive. The purpose of the present investigation was to evaluate communication between parent and neurosurgical team soon after resection of a pediatric brain tumor.

\section{Methods \\ Participants}

Study participant recruitment took place at a tertiary care hospital in the southeastern United States that diagnoses and treats 25 to 40 new pediatric patients with a brain tumor per year. Study participants were recruited as part of a larger study investigating psychosocial impact and distress after diagnosis of a pediatric brain tumor. ${ }^{10}$ Enrollment inclusion criteria were defined as any caregiver of a pediatric patient admitted to the hospital with a new brain tumor diagnosis. Enrollment occurred during an 18-month period in 2016-2017. Study participants were recruited during their child's initial neurosurgical inpatient hospitalization for removal of a brain tumor. Participant enrollment concluded on thematic saturation, when 2 consecutive interviews did not identify any novel themes or ideas. Sample characteristics are shown in Table 1 and have been previously reported. ${ }^{10}$

\section{Procedures}

Eligible participants were parents or primary caregivers of children newly diagnosed with a brain tumor. Consent was obtained during their child's initial hospital admission for surgical treatment of the tumor, prior to discharge from the hospital. Families had the option to decline participation in the interview portion of the study at the time of follow-up. Semistructured interviews were conducted with study participants at the time of routine follow-up visit in the neurosurgical outpatient clinic, within 3 months of their child's hospital discharge. Qualitative methods were used to obtain an in-depth understanding of the quality of communication between neurosurgeons and caregivers, and between members of the neurosurgical medical team (nurses, staff, technicians) and caregivers. Ethical approval was obtained from the University of Alabama at Birmingham's institutional review board.

Interviews were conducted by a psychology doctoral student trained in clinical research ethics and informed
TABLE 1. Demographic data for 22 participants in this study of provider communication after resection of pediatric brain tumors

\begin{tabular}{|c|c|}
\hline Variable & No. $(\%)$ \\
\hline \multicolumn{2}{|l|}{ Caregiver's sex } \\
\hline Male & $3(14 \%)$ \\
\hline Female & $19(86 \%)$ \\
\hline \multicolumn{2}{|l|}{ Marital status } \\
\hline Single & $7(31 \%)$ \\
\hline Married & $14(64 \%)$ \\
\hline Divorced & $1(5 \%)$ \\
\hline \multicolumn{2}{|l|}{ Caregiver's education } \\
\hline Less than high school & $2(9 \%)$ \\
\hline High school & $4(18 \%)$ \\
\hline Some college & $6(27 \%)$ \\
\hline Finished college & $6(27 \%)$ \\
\hline Some graduate school & $0(0 \%)$ \\
\hline Finished graduate school & $4(18 \%)$ \\
\hline \multicolumn{2}{|l|}{ Child's sex } \\
\hline Male & $12(55 \%)$ \\
\hline Female & $10(45 \%)$ \\
\hline \multicolumn{2}{|l|}{ Tumor histology } \\
\hline Benign & $5(23 \%)$ \\
\hline Malignant & $17(77 \%)$ \\
\hline \multicolumn{2}{|l|}{ Neurological status } \\
\hline No deficits or seizures & $10(45 \%)$ \\
\hline Mild deficits & $5(23 \%)$ \\
\hline Moderate deficits & $5(23 \%)$ \\
\hline Severe deficits & $2(9 \%)$ \\
\hline
\end{tabular}

consent, and in qualitative data collection and analysis. Interviews took place within 3 months after discharge and occurred in an outpatient clinic facility located within the hospital. The interviewer used an interview guide that focused on open-ended questions designed to obtain information about the quality of communication with the neurosurgery medical team during hospitalization, as well as hospital services provided. Interviews began with broad questions about caregivers' interactions with the neurosurgical team during their child's diagnosis and resection of a brain tumor. Caregivers were asked specifically about the quality of communication with the neurosurgery medical team during hospitalization. Interviews were audio-recorded, transcribed, and coded for common themes. Table 2 contains sample interview questions and suggested probes.

\section{Data Analysis}

This study used a qualitative design, details of which can be found in our previous publication. ${ }^{10}$ Development of coding criteria was based on a phenomenological approach to allow for a detailed thematic classification of communication experiences. Transcriptions of interviews were reviewed, and caregiver descriptions of information transfer and communication with the neurosurgi- 
TABLE 2. Interview question and probes in this study of provider communication after resection of pediatric brain tumors

Excerpt From Interview Guide

\begin{tabular}{cc}
\hline Question & $\begin{array}{c}\text { How would you describe communication between you and } \\
\text { the medical team during your child's hospitalization? }\end{array}$ \\
\hline Probes & Were all of your questions answered? \\
& Did the physician make sure you understood all of the \\
information? \\
How could communication have been improved?
\end{tabular}

cal team were coded for common themes. Coding criteria were determined by 3 of the authors, a psychology doctoral student with experience working with families in medical settings (A.C.), a neurosurgeon with experience treating patients with brain tumors (B.G.R.), and a health behavior researcher with expertise in qualitative methods (S.D.). These 3 individuals each independently coded interviews and then collaboratively resolved any coding discrepancies until reaching agreement on how to create/categorize codes. Final codes were clearly defined on a coding sheet. At the conclusion of interview coding by the psychology graduate student, all interview codes were reviewed. Validation checks were performed by each member of the team individually coding one-third of interviews.

Clinical and demographic variables were collected from a review of the electronic medical records. Variables obtained included caregiver's sex, caregiver's marital status, caregiver's education, child's sex, child's age, tumor histology, and neurological status.

\section{Results}

Twenty-two caregivers participated in the study. Forty parents enrolled in the original study and were eligible for interview. They were approached sequentially when returning for clinic follow-up. No family declined to participate in the interviews. Enrollments ended at 22 when thematic saturation was reached. Demographic and clinical characteristics are described in Table 1. Two main themes of communication emerged from caregiver interviews: positive experiences and negative experiences (Tables 3 and 4). Positive experiences included the following: 1) family felt well prepared; 2) physician communication was thorough; 3) communication was direct and clear; 4) information was easily understandable; and 5) physicians made an effort in communication. Negative experiences included the following: 1) family was required to repeat information multiple times; 2) miscommunication; 3) breakdown in communication; 4) diagnosis discussed in front of child prematurely; 5) lack of clarity when information provided; 6) caregiver had to lead communication; and 7) caregiver was overwhelmed with information.

\section{Positive Feedback About Communication With Medical Team}

Family Felt Well Prepared

Caregiver cited that communication prepared the pa- tient and family for both surgery and to leave the hospital (“... I was confident that I knew what was about to happen").

\section{Communication With Physicians Was Very Thorough}

Caregivers appreciated when the medical team discussed possibilities upfront (" $\ldots$ the doctors were very thorough when explaining what it could be, and the worst it could be, and then the best") and when all questions were answered ("everybody's been very ... patient in letting me ask my questions, answering them....").

\section{Communication Was Direct and Clear}

Honest communication ("He was honest with us from the get-go.... I would rather it not be sugarcoated.") and direct communication ("They basically just said it [...]. Which now, looking back, I appreciate it because if he would have beat around the bush I could have misconstrued it easily.") were highly valued by caregivers.

\section{Information Was Easily Understandable to Family}

Caregivers appreciated the medical team using language easily understandable by nonmedical persons, and when the medical team spoke directly to the patient ("One thing that I really appreciated ... is that when the team would come into the room, they would talk to [patient].”).

\section{Efforts Made by Physician to Provide Clear Information and to Comfort Family}

Caregivers stated having positive experiences from a compassionate surgeon ("... I could just hear the hurt in his voice when he was telling me.") and when the medical team exceeded expectations in providing their child with the most comfort possible.

\section{Negative Feedback About Communication With Medical Team}

\section{Family Was Required to Repeat Information Multiple Times}

Many families reported negative experiences in regard to repeating information about their child's diagnosis multiple times, and to individuals perceived as not part of their child's care team ("My biggest pet peeve is having somebody come in that really doesn't need to know information, ask me information....").

\section{Miscommunication Between Family and Medical Team}

Subthemes in miscommunication included: questions unanswered or family unsure of what to ask ("I can't even pronounce the diagnosis. I don't know."), and that members of the team had conflicting or incorrect information due to physicians rotating service ("If one was saying something different [than I'd heard from other doctors] I'm like 'whoa'....").

\section{Breakdowns in Communication Between Parent and Medical Team}

Many caregivers reported that breakdowns in communication between the family and medical team about the patient's medical needs had a negative impact on the care the patient received ("Throughout the stay, over and over 
TABLE 3. Quotes illustrating parent feedback regarding communication with medical team after child's treatment for brain tumor

\begin{tabular}{|c|c|}
\hline Feedback & Quotes \\
\hline \multicolumn{2}{|l|}{ Positive } \\
\hline $\begin{array}{l}\text { Family felt well pre- } \\
\text { pared, both for surgery } \\
\text { and to leave hospital }\end{array}$ & $\begin{array}{l}\text { "Everything was explained pretty thoroughly and I can't, you know, recite all the technical terms but I understood most of } \\
\text { it and got the basics of it. Enough to know that I was confident that I knew what was about to happen." }\end{array}$ \\
\hline $\begin{array}{l}\text { Communication with } \\
\text { physician was very } \\
\text { thorough }\end{array}$ & $\begin{array}{l}\text { Discussed range of possibilities up front: "Yeah, the doctors were very thorough when explaining what it could be, and the } \\
\text { worst it could be, and then the best. So, I was aware of all the possibilities and my imagination was running. So, finding } \\
\text { out that it was one of the better case scenarios was a big load off my mind." } \\
\text { "We had a lot of faith in him going in because he told us, he was honest with us from the get-go. He told us how bad that } \\
\text { it could possibly be, but he also told us, you know, it could go a different route. It could be totally different than we were } \\
\text { expecting. He didn't, he didn't lead us into believing that, you know, that she was going to be as good as she is." } \\
\text { All questions answered: "Everybody's been very ... patient in letting me ask my questions, answering them, even if they } \\
\text { are completely off the wall and it has nothing to do with, but it's something like I may have read thinking that maybe this } \\
\text { is why we're having this hiccup or that hiccup." }\end{array}$ \\
\hline $\begin{array}{l}\text { Communication was } \\
\text { direct and clear }\end{array}$ & $\begin{array}{l}\text { "He was honest with us from the get-go.... I would rather it not be sugarcoated. I want to know what my child is actually } \\
\text { going through." } \\
\text { "[when giving diagnosis] They basically just said it [bluntly]. Which now, looking back, I appreciate because if he would } \\
\text { have beat around the bush I could have misconstrued it easily. So I was glad he was very direct." } \\
\text { "[his surgeon] explained it like the alphabet. He said, 'we're at letter A. And we're not gonna talk about C, D, E, F, or Z until } \\
\text { we get past A.' You know. And that was a very, like, in that moment that was very easy for me to think, 'Okay, I need to } \\
\text { focus on A.' And so that's kind of what I did. He's like 'today is surgery, we're at letter A. We'll talk about letter B tomor- } \\
\text { row morning.'" }\end{array}$ \\
\hline $\begin{array}{l}\text { Information was eas- } \\
\text { ily understandable to } \\
\text { family }\end{array}$ & $\begin{array}{l}\text { "On our level": "When [the surgeon] would come in, and he'd sit down at our level and talk to us.... [My mother] said she } \\
\text { was just so impressed with [the surgeon]. How he came in and just sat down with her, and, you know, she said 'What a } \\
\text { difference!' Of her experience seeing the way she's treated here." } \\
\text { Spoke directly to patient: "One thing that I really appreciated ... is that when the team would come into the room, they } \\
\text { would talk to [patient]." }\end{array}$ \\
\hline $\begin{array}{l}\text { Efforts made by physi- } \\
\text { cian to provide clear } \\
\text { information and to } \\
\text { comfort family }\end{array}$ & $\begin{array}{l}\text { Compassionate surgeon: "I could just tell - I mean I could just hear the hurt in his voice when he was telling me. You } \\
\text { know, he just was so - felt so bad, you know, he had to give me that kind of news." }\end{array}$ \\
\hline \multicolumn{2}{|l|}{ Negative } \\
\hline $\begin{array}{l}\text { Family was required } \\
\text { to repeat information } \\
\text { multiple times }\end{array}$ & $\begin{array}{l}\text { "My biggest pet peeve is having somebody come in that really doesn't need to know information, ask me information.... } \\
\text { To a parent whose child has a long medical history, nothing is more upsetting and aggravating than for somebody who } \\
\text { you know is not part of the team to come in and ask you what's going on.... They need history to know how to stabilize } \\
\text { the kid. But they do not need to know their whole history. And we don't need repeated people asking. Because it just } \\
\text { aggravates the situation." }\end{array}$ \\
\hline $\begin{array}{l}\text { Miscommunication } \\
\text { between family and } \\
\text { medical team }\end{array}$ & $\begin{array}{l}\text { Questions unanswered or family unsure what to ask: "I can't even pronounce [the diagnosis]. I don't know. They were } \\
\text { supposed to write it down for us, but I never got them to." } \\
\text { Members of the medical team had conflicting or incorrect information: "They would switch out, the doctors, they rotate. If } \\
\text { one was saying something different [than l'd heard from other doctors] I'm like 'whoa'... I would even bring up some- } \\
\text { times, like, 'Well, so and so told me this.' Or, 'This is what I've been told."' }\end{array}$ \\
\hline $\begin{array}{l}\text { Breakdowns in commu- } \\
\text { nication between parent } \\
\text { and medical team }\end{array}$ & $\begin{array}{l}\text { "Throughout the stay, over and over and over again communication was broken down numerous times, just between } \\
\text { transport and her going down, she couldn't manage her secretions so she has to have suction constantly, and they } \\
\text { would not relay that message to who was down there so we would get down there and get in trouble and there wouldn't } \\
\text { be suction set up for her." }\end{array}$ \\
\hline $\begin{array}{l}\text { Diagnosis of brain tumor } \\
\text { discussed in front of } \\
\text { patient before CG was } \\
\text { prepared to share this } \\
\text { information with patient }\end{array}$ & $\begin{array}{l}\text { "[Physician] came in and she said, 'Well I understand you're here for a brain tumor' and I was like 'oh my gosh!... We have } \\
\text { not talked to him! Because we literally just found this out.... He thinks he is here for a headache." }\end{array}$ \\
\hline
\end{tabular}


TABLE 3. Quotes illustrating parent feedback regarding communication with medical team after child's treatment for brain tumor

\begin{tabular}{|c|c|}
\hline Feedback & Quotes \\
\hline \multicolumn{2}{|l|}{ Negative (continued) } \\
\hline $\begin{array}{l}\text { Lack of clarity when } \\
\text { information provided }\end{array}$ & $\begin{array}{l}\text { Lack of clarity about pain medication: "... then they told us that his pain medicine is 'as needed.' Well, he's } 9 \text { months old. } \\
\text { How do we know?" } \\
\text { Lack of clarity about Iong-term effects of diagnosis and treatment: "I just want to know about development stuff, 'cause I } \\
\text { worry about that. 'Cause he has a hole in his brain, so...." } \\
\text { Lack of clarity about services offered: "The different nurses would say different things and they weren't sure, and I didn't } \\
\text { know who to talk to [to] find out about it. And eventually I just said never mind...." } \\
\text { Unclear what to expect/prepare for: "the original surgery he was going to make a small incision ... I never heard the word } \\
\text { 'craniotomy.' I guess I was shocked when I saw her incision ... I didn't realize he was gonna have to open up the whole } \\
\text { side of her head.... That was the only thing that I wish he had kind of mentioned. I mean, he said the scope of the } \\
\text { surgery had changed, I know his focus and I know it all happened quick and all that. But that was the only thing that I } \\
\text { felt like I missed. You know, I would have liked to know, you know, what to expect." } \\
\text { "It was quite overwhelming because we didn't know what was really happening, I guess? I mean they said we were gonna } \\
\text { be admitted, but it would have been helpful to have that conversation of 'Okay. Y'all are gonna be admitted. This is } \\
\text { what, this is what ... to expect.". } \\
\text { Unclear about diagnosis, hospitalization, plan for treatment: "I'm a nurse ... that's what I do. So when they would talk and } \\
\text { I would just kind of listen and I just heard bits and pieces of what they were saying about her, thinking, okay, they told } \\
\text { me she had a tumor but it wasn't, it wasn't detailed enough for me to know, okay, what to expect, what's gonna be the } \\
\text { outcome, what's gonna be the treatment options." } \\
\text { Lack of clarity about postdischarge care: "I called them that Monday and I was like, 'Yeah, I need to set up my son's } \\
\text { postop appointment.' And they said 'Oh, well it's already set up on the 30th at 8:45...' I didn't have, like, 'Okay. Here's a } \\
\text { list of your appointments. Here's who you're gonna see." }\end{array}$ \\
\hline $\begin{array}{l}\text { CG needed to be proac- } \\
\text { tive and lead commu- } \\
\text { nication }\end{array}$ & $\begin{array}{l}\text { "You had to know what to ask, you were supposed to know what was going on ... seemed like it was up on us to get stuff } \\
\text { done." } \\
\text { "And now l've got to remember to call you ... since we've been home, there's been a lot of me reaching out instead of } \\
\text { somebody reaching out to us. And I think that would be beneficial." }\end{array}$ \\
\hline $\begin{array}{l}\text { CG was overwhelmed } \\
\text { with information }\end{array}$ & $\begin{array}{l}\text { "Lots of people coming in and explaining, or trying to explain, like, what all was happening at the time. Just very over- } \\
\text { whelming and a lot of information given in a very short period of time. So, I'm not sure actually how much I was able to } \\
\text { process the first } 48 \text { hours because he had surgery the next day." }\end{array}$ \\
\hline
\end{tabular}

$C G=$ caregiver.

and over again communication was broken down numerous times....").

Diagnosis of Brain Tumor Discussed in Front of Patient Before Caregiver Was Prepared to Share This Information With Patient

Fourteen percent of caregivers stated that their child's diagnosis was told to the patient before the caregiver had an opportunity to discuss the diagnosis and treatment course with their child.

\section{Lack of Clarity When Information Provided}

Lack of clarity was a negative experience endorsed by $32 \%$ of caregivers. Subthemes included 1) lack of clarity about pain medications; 2) lack of clarity about long-term effects of diagnosis and treatment; 3 ) lack of clarity about services offered; 4) unclear what to expect/prepare for; 5) unclear about diagnosis, hospitalization, plan for treatment; and 6) lack of clarity about postdischarge care.

\section{Caregiver Needed to be Proactive and Lead Communication}

Caregivers reported not receiving the follow-up communication and advocacy they were expecting to ("since we've been home, there's been a lot of me reaching out instead of somebody reaching out to us. And I think that would be beneficial.").

\section{Caregiver Was Overwhelmed With Information}

Too many individuals communicating information, and too much information in a short period of time led to negative experiences for many caregivers ("Lots of people coming in and explaining, or trying to explain, like, what all was happening at the time. Just very overwhelming and a lot of information given in a very short period of time."').

\section{Discussion}

The purpose of this study was to qualitatively evaluate communication between families and healthcare providers, particularly the surgical team, in the time surrounding the diagnosis of a pediatric brain tumor. This is typically a very stressful time. In most cases, shortly after the tumor is discovered, the child is admitted to a hospital and undergoes a surgical procedure, for biopsy or resection of the tumor. This is followed by a hospital stay while the child is recovering from surgery and a period of uncertainty before the histological tumor diagnosis is available.

In our previous work, we have shown that families have high levels of distress during this time period. ${ }^{10,11}$ For many families, the experience of having a child with a brain tumor will be the most stressful and devastating experience of their entire life. Diagnosis, treatment, inpatient 
TABLE 4. Communication between parent and medical team after child's brain tumor resection

\begin{tabular}{|c|c|c|}
\hline Feedback About Communication w/ Medical Team & No. & $\%$ \\
\hline \multicolumn{3}{|l|}{ Positive } \\
\hline Doctor prepared family well & 6 & 27 \\
\hline Doctor very thorough & 16 & 73 \\
\hline Discussed range of possibilities up front & 2 & 9 \\
\hline All questions answered & 16 & 73 \\
\hline Direct/clear & 6 & 27 \\
\hline \multicolumn{3}{|l|}{ Information easily understood by family } \\
\hline "On my level" & 4 & 18 \\
\hline Spoke directly to patient & 6 & 27 \\
\hline Efforts made for clear communication/comforting family & 7 & 32 \\
\hline Compassionate surgeon & 3 & 14 \\
\hline Above and beyond & 3 & 14 \\
\hline Total & 18 & 82 \\
\hline \multicolumn{3}{|l|}{ Negative } \\
\hline Having to repeat information multiple times & 2 & 9 \\
\hline Miscommunication & 7 & 32 \\
\hline Questions unanswered/unsure what to ask & 3 & 14 \\
\hline Members of team have conflicting information & 5 & 23 \\
\hline $\begin{array}{l}\text { Breakdowns in communication between parent and } \\
\text { medical team }\end{array}$ & 4 & 18 \\
\hline Diagnosis discussed in front of patient before CG ready & 3 & 14 \\
\hline Lack of clarity & 7 & 32 \\
\hline Lack of clarity about pain medications & 2 & 9 \\
\hline Lack of clarity about long-term effects & 3 & 14 \\
\hline Lack of clarity about services offered & 2 & 9 \\
\hline Unclear what to expect/prepare for & 4 & 18 \\
\hline $\begin{array}{l}\text { Unclear about diagnosis/plan for treatment/ } \\
\text { hospitalization }\end{array}$ & 4 & 18 \\
\hline Lack of clarity about postdischarge care & 2 & 9 \\
\hline CG needed to be proactive and lead communication & 3 & 14 \\
\hline Overwhelming information & 2 & 9 \\
\hline Total & 12 & 55 \\
\hline
\end{tabular}

stay, and follow-up can be hectic and confusing experiences. Caregivers are given a large amount of information that is difficult to process in a short period of time; this information is given by many different members of the care team, which can result in the information being disjointed; and information is often provided in medical terminology, which may be nearly impossible for caregivers to understand without prior medical knowledge. Caregivers want to advocate for their child, but this can be extremely difficult when communication from care providers is not clear. This situation can lead to feelings of alienation, frustration, and resentment toward the medical team. Establishing clear, effective, and honest communication between neurosurgeons and caregivers of pediatric patients with brain tumors is an essential component to providing the highest quality of care to pediatric patients.

Favorable communication between parents and the medical team during this stressful time might be helpful in reducing distress and helping families cope. We have conducted this study to determine both what is working well and what potential areas of improvement exist in this specific type of patient/physician communication.

The majority of parents interviewed had an overall favorable impression of their communication with physicians and other team members. Families had positive impressions when communication was clear and direct, thorough, and easily understandable. Parents reported communications that helped them feel prepared for what was to come as positive experiences.

Although it is important to note the positive experiences, it is probably more important to carefully study the negative perceptions that families had of their communication experience, because these are areas where improvement is possible. The most common aspect of communication that parents identified as negative was lack of clarity. Specifically, parents noted lack of clarity about diagnosis, treatment plans, and what to expect. This probably reflects the uncertainty after resection or biopsy of a tumor before a histological diagnosis is available. During the wait for the pathology result, the treatment team is unable to provide counseling about the next steps or prognosis-all of this is contingent on the tumor diagnosis. So although it may not be possible to provide immediate, clear answers to all of a parent's questions, the treatment team can provide consistent information about the hospital course while waiting for a diagnosis.

Other common negative experiences reported by parents are miscommunication or breakdown in communication. Parents mention being given conflicting information by different individuals they encountered during the hospital stay. This illustrates the importance of assuring that the treatment plan is clearly defined, and that all team members are aware of the plan. Avoiding miscommunication with the family requires avoiding miscommunication between members of the care team.

Other studies of communication between providers and caregivers have found similar results. In a study of critically ill patients conducted at Cincinnati Children's Hospital Medical Center, results showed that positive communication themes included caregivers feeling like part of the team, and negative themes included feeling out of the loop, insufficient face time with physicians, and use of medical jargon. ${ }^{9}$ In a qualitative study of caregivers' experiences within an inpatient neurology and neurosurgery hospital setting, results indicated that lack of a clear line of communication and dialog from the care team was a challenge faced by caregivers. ${ }^{12}$

Partly as a result of the information gathered in this study, our institution has established a nonclinical navigator program for families of children with brain tumors. This is modeled after a similar program that was successfully implemented in the adult oncology department of the parent institution. ${ }^{13}$ At the time of initial hospital admission with the new diagnosis of a CNS tumor, each child and family is assigned a lay navigator. The navigator conducts an initial assessment, including administering the psychosocial assessment tool to determine the family's risk level. ${ }^{11}$ Based on the results of these surveys, hospital 
resources are made available to the family to provide the needed support. The navigator makes regular follow-up visits with the patient and family and communicates regularly with the treatment team regarding family questions or difficulties with communication. We are hopeful that a navigator can serve as a single point of contact during both inpatient stay and outpatient follow-up. Furthermore, the navigator can coordinate communication from many different providers involved in the care of these patients. Formal analysis of the effect of this navigation program is not available.

This study has several limitations. Interviews were conducted with family members at the time of their initial outpatient follow-up visit. The initial visit was typically approximately 2 weeks after hospital discharge. However, not all interviews could be conducted in this time frame. Because there is variability in the timing of interviews, there may be a recall bias, with families remembering some aspects of communication better than others. In addition, all of the interviews were conducted after the pathological diagnosis was known. Of course, expected survival and prognosis depend largely on tumor diagnosis. It is possible that parents of children with high-grade tumors may have different impressions of their hospital experience than those with low-grade tumors. However, in a previous qualitative study of coping mechanisms in this population, we showed no significant differences between parents of patients with high-grade and low-grade tumors. ${ }^{10}$ The study was conducted at a single institution. Issues with communication, both positive and negative, may be different at other institutions, and this may limit the generalizability of our findings.

\section{Conclusions}

Although the results of this study found that many parents have a positive impression in regard to communication with their physicians and patient care team, many caregivers also reported negative experiences. Improving the communication between the clinical care team and parents of pediatric patients with a brain tumor represents a key opportunity to improve quality of care.

\section{Acknowledgments}

This work was supported by NIH grant 1KL2TR001419.

\section{References}

1. Barraza M. The right thing. Narrat Inq Bioeth. 2014;4(1): 39-42.

2. Palmer SL, Lesh S, Wallace D, et al. How parents cope with their child's diagnosis and treatment of an embryonal tumor: results of a prospective and longitudinal study. J Neurooncol. 2011;105(2):253-259.

3. Woodgate RL, Tailor K, Yanofsky R, Vanan MI. Childhood brain cancer and its psychosocial impact on survivors and their parents: a qualitative thematic synthesis. Eur J Oncol Nurs. 2016;20:140-149.
4. Dunn MJ, Rodriguez EM, Barnwell AS, et al. Posttraumatic stress symptoms in parents of children with cancer within six months of diagnosis. Health Psychol. 2012;31(2):176-185.

5. Rodriguez EM, Dunn MJ, Zuckerman T, et al. Cancer-related sources of stress for children with cancer and their parents. $J$ Pediatr Psychol. 2012;37(2):185-197.

6. Greenberg JA, Gerhart J, Horst JN, et al. A multidisciplinary team-based approach to improve communication with surrogates of patients with chronic critical illness. Am J Hosp Palliat Care. 2020;37(3):214-221.

7. Wanzer MB, Booth-Butterfield M, Gruber K. Perceptions of health care providers' communication: relationships between patient-centered communication and satisfaction. Health Commun. 2004;16(3):363-383.

8. Schubart JR, Kinzie MB, Farace E. Caring for the brain tumor patient: family caregiver burden and unmet needs. Neuro Oncol. 2008;10(1):61-72.

9. Solan LG, Beck AF, Shardo SA, et al. Caregiver perspectives on communication during hospitalization at an academic pediatric institution: a qualitative study. J Hosp Med. 2018;13(5):304-311.

10. Cutillo A, Zimmerman K, Davies S, et al. Coping strategies used by caregivers of children with newly diagnosed brain tumors. J Neurosurg Pediatr. 2018;23(1):30-39.

11. Rocque BG, Cutillo A, Zimmerman K, et al. Distress and psychosocial risk in families with newly diagnosed pediatric brain tumors. J Neurosurg Pediatr. 2018;23(1):40-47.

12. Khabarov D, Dimitropoulos G, McGillicuddy P. Qualitative study: exploring the experiences of family caregivers within an inpatient neurology and neurosurgery hospital setting. Health Soc Work. 2015;40(4):290-297.

13. Rocque GB, Partridge EE, Pisu M, et al. The Patient Care Connect Program: transforming health care through lay navigation. J Oncol Pract. 2016;12(6):e633-e642.

\section{Disclosures}

The authors report no conflict of interest concerning the materials or methods used in this study or the findings specified in this paper.

\section{Author Contributions}

Conception and design: Rocque, Cutillo, Davies, Madan-Swain, Landier. Acquisition of data: Rocque, Cutillo, Arynchyna. Analysis and interpretation of data: all authors. Drafting the article: all authors. Critically revising the article: all authors. Reviewed submitted version of manuscript: all authors. Approved the final version of the manuscript on behalf of all authors: Rocque. Statistical analysis: Rocque, Cutillo, Davies, Arynchyna. Administrative/ technical/material support: Rocque, Cutillo, Arynchyna. Study supervision: Rocque, Davies, Madan-Swain, Landier.

\section{Correspondence}

Brandon G. Rocque: University of Alabama at Birmingham, AL. brandon.rocque@childrensal.org. 